\title{
The extracellular proteome of two Bifidobacterium species reveals different adaptation strategies to low iron conditions
}

\author{
Pamela Vazquez-Gutierrez ${ }^{1}$, Marc J. A. Stevens ${ }^{1 \dagger}$, Peter Gehrig ${ }^{2}$, Simon Barkow-Oesterreicher ${ }^{2}$, \\ Christophe Lacroix $^{1 *}$ and Christophe Chassard ${ }^{1,3+}$
}

\begin{abstract}
Background: Bifidobacteria are among the first anaerobic bacteria colonizing the gut. Bifidobacteria require iron for growth and their iron-sequestration mechanisms are important for their fitness and possibly inhibit enteropathogens. Here we used combined genomic and proteomic analyses to characterize adaptations to low iron conditions of B. kashiwanohense PV20-2 and B. pseudolongum PV8-2, 2 strains isolated from the feces of iron-deficient African infants and selected for their high iron-sequestering ability.

Results: Analyses of the genome contents revealed evolutionary adaptation to low iron conditions. A ferric and a ferrous iron operon encoding binding proteins and transporters were found in both strains. Remarkably, the ferric iron operon of B. pseudolongum PV8-2 is not found in other B. pseudolongum strains and likely acquired via horizontal gene transfer. The genome $B$. kashiwanohense PV20-2 harbors a unique region encoding genes putatively involved in siderophore production.

Additionally, the secretomes of the two strains grown under low-iron conditions were analyzed using a combined genomic-proteomic approach. A ferric iron transporter was found in the secretome of B. pseudolongum PV8-2, while ferrous binding proteins were detected in the secretome of B. kashiwanohense PV20-2, suggesting different strategies to take up iron in the strains. In addition, proteins such as elongation factors, a glyceraldehyde-3-phosphate dehydrogenase, and the stress proteins GroEL and DnaK were identified in both secretomes. These proteins have been previously associated with adhesion of lactobacilli to epithelial cells.
\end{abstract}

Conclusion: Analyses of the genome and secretome of B. kashiwanohense PV2O-2 and B. pseudolongum PV8-2 revealed different adaptations to low iron conditions and identified extracellular proteins for iron transport. The identified extracellular proteins might be involved in competition for iron in the gastrointestinal tract.

Keywords: Bifidobacterium kashiwanohense, Bifidobacterium pseudolongum, Iron binding, Genomics, Proteomics

\section{Background}

Iron is an essential micronutrient for most organisms and is taken up by high affinity transport systems [1]. Two oxidized forms of iron, ferric $\left(\mathrm{Fe}^{3+}\right)$ and ferrous iron $\left(\mathrm{Fe}^{2+}\right)$, occur in nature with ferrous iron being to be most abundant in the intestine [2]. Iron is limited in most environments and a battle for iron occurs in many microbial ecosystems, including the human gastro-

\footnotetext{
* Correspondence: christophe.lacroix@hest.ethz.ch

${ }^{\dagger}$ Equal contributors

'Laboratory of Food Biotechnology, ETH Zurich, Institute of Food, Nutrition

and Health, Schmelzbergstrasse 7, 8092 Zurich, Switzerland

Full list of author information is available at the end of the article
}

intestinal (GI) tract [3, 4]. Withholding iron is therefore a competitive and defense trait in many Gram-positive and Gram-negative bacteria [5, 6]. Predominant members of an ecosystem frequently possess efficient ironscavenging systems which enable them to outcompete other microorganisms by depriving them from iron [7]. In addition, restricting iron to pathogens in the GI-tract has been coined as nutritional immunity phenomenon and is usually associated with efficient iron-sequestration systems.

Bifidobacteria are non-sporeforming, nonmotile, anaerobic, Gram-positive bacteria with a high $\mathrm{G}+\mathrm{C}$ content that are residents of the GI-tract and predominant 
in infants [8]. Bifidobacteria have been shown to beneficially modulate the composition and activity of the intestinal microbiota, to prevent bacterial infections, and to exert anti-inflammatory and immunomodulation activities [9]. These beneficial traits depend strongly on the ability of a strain to survive and to adapt in the GI-tract [10]. Adaptation and survival involve the use of efficient and diverse nutrient uptake systems, enzymes, stress proteins, and factors that interact with the host and with other members of the gut microbiota [11].

Bifidobacteria require iron for growth and produce extracellular binding proteins that are involved in iron uptake [12]. Such iron-binding proteins may also be implicated in iron withholding thereby limiting the availability to pathogens in the GI-tract [13]. Additionally, the essential micronutrient zinc might have a similar role in ecosystems as iron, and mechanisms for zinc sequestration have been recently reported to further contribute to nutritional immunity by similar mechanisms as iron sequestration [14-16].

Bacterial extracellular proteins are either actively transported through the cytoplasmic membrane into the environment or simply shed from the surface. The composition of the extracellular proteome, also known as the secretome, strongly depends on the nutrient preferences of the bacterium [17]. Bifidobacterial secretomes have been used to study diversity and physiology of the genus, and to identify differences in nutrient uptake and stress response $[18,19]$. Extracellular proteins of bifidobacteria are pivotal for host interactions and -adaptations, for nutrient uptake, adhesion, and stress sensing [20-24]. Further, extracellular proteins of bifidobacteria are potentially directly involved in mechanisms beneficial to the host [25], and the secretome is therefore an ideal target to understand interactions and responses of bifidobacteria in the GI-tract.

Functional genomics is powerful to identify bifidobacterial mechanisms active in the gut, such as genes involved in host-microbe interactions, the degradation of human milk oligosaccharides, or pili encoding genes $[10,23]$. Combined genomic and proteomic analyses of bifidobacteria revealed mechanisms of adaptation to the GI-tract and genetic functions that mediate specific hostmicrobe and microbe-microbe interactions [26, 27]. In contracts to genomics, proteomic detects the functional gene products that are present under specific conditions $[28,29]$. Proteomic also allows comparison of strain specific features under similar conditions and is therefore well suited for studying features which may not be accessed by genomics [28]. However, analyses of proteomic mass spectra (MS) rely upon homology with pre-established protein sequences derived from genus related databases [30]. Such approach will inevitably fail to identify strain-unique protein sequences [22] and because many bifidobacterial properties are strain specific, homology-driven proteomics has limits to identify important phenotypic features [19]. A combined genomic-proteomic approach in which the genome is sequenced and used to build a protein database is therefore more suitable for the analyses of the proteomic MS data form bifidobacteria.

Bifidobacterium kashiwanohense PV20-2 and Bifidobacterium pseudolongum PV8-2 were isolated from the feces of breast-fed, anemic Kenyan infants. These strains exhibit high iron sequestration mechanisms and their whole genomes have been sequenced [12, 31, 32]. In this study, the genomes of $B$. kashiwanohense PV20-2 and $B$. pseudolongum PV8-2 were compared to other bifidobacterial genomes to identify genes potentially involved in iron metabolism. Further, we identified the secretome of both strains under iron limiting conditions using a combined genomic-proteomic approach. In this approach, the predicted coding sequences were used to identify MS/MS-peptides obtained via a 1D gel-based shotgun proteomic approach.

\section{Results \\ Comparative genome analyses of $B$. kashiwanohense PV20-2}

B. kashiwanohense PV20-2 (PV20-2) and B. pseudolongum PV8-2 (PV8-2) were selected for their high iron sequestration in a screening of 56 bifidobacterial strains isolated from the feces of anemic infants in Kenya [12]. To analyze whether specific adaptations related to iron uptake were present in the genomes, we compared the complete genomes of PV20-2 and PV8-2 to 82 completely or partially sequenced bifidobacterial genomes (Additional file 1: Table S1).

The genome of PV20-2 contains 2077 CDSs. A comparison to 82 bifidobacterial genomes, including that of $B$. kashiwanohense strain DSM 21854, revealed 58 CDSs unique for PV20-2, of which 55 encode hypothetical functions (Additional file 2: Table S2). Interestingly, the two unique CDSs AH68_05490 and AH68_05500 are located in a region containing genes that are not or rarely found in other bifidobacteria (region AH68_05460-05520). Refined analyses of the genes in this region revealed that they have high homology to non-ribosomal peptide synthesis genes. Moreover, a conserved domain search [33] shows that the protein encoded by AH68_05485 contains a non-ribosomal peptide synthesis domain (e-score $=9.28 \mathrm{e}-127$ ). This protein has only one poor hit in the genome comparison, in Bifidobacterium adolescentis L2-32 (e-score =3.14e-14). The $560 \mathrm{AA}$ at the C-terminus of this CDS share 33\% identity and $52 \%$ similarity with a bacillibactin synthetase from Bacillus subtilis 168 [34], and 26\% identity and $48 \%$ similarity with a pyoverdine synthetase from Pseudomonas aeruginosa [35], both enzymes involved in siderophore biosynthesis. Upstream of the putative 
siderophore synthesis genes an $\mathrm{ABC}$-transporter is located (AH68_05505).

Additionally, PV20-2 was compared solely to the type strain B. kashiwanohense DSM 21854 [23]. PV20-2 contained 252 proteins not found in DSM 21854. Of these proteins, 197 were found in one or more of the 82 bifidobacterial genomes used in this study (Additional file 1: Table S1 and Additional file 2: S2). Of these 197 CDSs, 47 had highest homology to proteins in B. longum strains, followed by Bifidobacterium adolescentis (32 CDSs), Bifidobacterium pseudocatenulatum (24) and Bifidobacterium breve (22). Finally, PV20-2 contained a ferrous and a ferric operon (Fig. 1), both also present in strain DSM 21854.

Comparative genome analyses of $B$. pseudolongum PV8-2 In parallel, B. pseudolongum PV8-2 was compared to the 82 bifidobacterial genomes and separately to the two available genomes of the species; $B$. pseudolongum AGR 2145 (fecal calf isolate) and B. pseudolongum subsp. globosum DSMZ 20092 (rumen isolate). The genome of PV8-2 harbored 1552 protein encoding genes of which 22 were not found in any other bifidobacterial genomes (Additional file 3: Table S3). The products of these 22 CDS encoded hypothetical or phage related functions. A total 78 CDSs did not have homologs in the two B. pseudolongum strains, of which 56 were found in other bifidobacterial genomes (Additional file 3: Table S3). Two larger insertions were found in the PV8-2 genome. One insertion encodes genes for arabinogalactan transport and utilization (AH67_01080-01120) that are organized in a similar order as in B. adolescentis ATCC 15703 (data not shown). In addition, two galactosidases (AH67_0181 and AH67_1596) were identified in PV-8-2 and not in the other $B$. pseudolongum strains, which might be involved in degradation of the galactose moiety of arabinogalactan. A second insertion contains an iron $\mathrm{ABC}$ transporter operon consisting of a ferric iron binding protein (AH67_02660), two membrane components (AH67_02665 and 02670), and the ATP-binding protein (AH67_02675). Detailed comparison of the corresponding genome regions of the three $B$. pseudolongum strains showed a highly conserved organization, with exception of the iron operon (Fig. 2), strongly suggesting that the operon has been acquired by PV8-2. The GC -content of the insertion is $59.4 \%$, only slightly lower than that of the genome $(62.4 \%)$. The encoded proteins were found only in an unknown faecal isolate belonging to the Actinobacteria phylum and in the rumen isolate Bifidobacterium sp. AGR2156 (cut off 80\% similarity).

Besides the ferric iron operon described above, also a ferrous iron transporter was predicted in PV8-2 (AH67_05680, Fig. 1). This transporter is also found in the other two B. pseudolongum strains and a BLAST search revealed that it is present in many bifidobacteria (data not shown).

\section{Secretome analysis of $B$. kashiwanohense PV20-2 and B. pseudolongum PV8-2 under low iron conditions} The iron uptake mechanisms of PV20-2 and PV8-2 were further studied by secretome analyses during growth under low iron conditions. The strains were grown in a chemically semi-defined medium with a low iron concentration of $1.5 \mu \mathrm{M}$ [12] and extracellular proteins were isolated and identified by LC/MS. A total of 112 proteins were identified in the secretome of PV20-2 (Additional file 4: Table S4) of which 34 (30\%) were predicted to contain a classical signal peptide, 46 (41\%) were predicted to be secreted by a non-classical
Ferric operon
B. kashiwanohense PV20-2

Ferric operon

B. pseudolongum PV8-2

Ferrous operon B. kashiwanohense PV20-2

Ferrous operon B. pseudolongum PV8-2
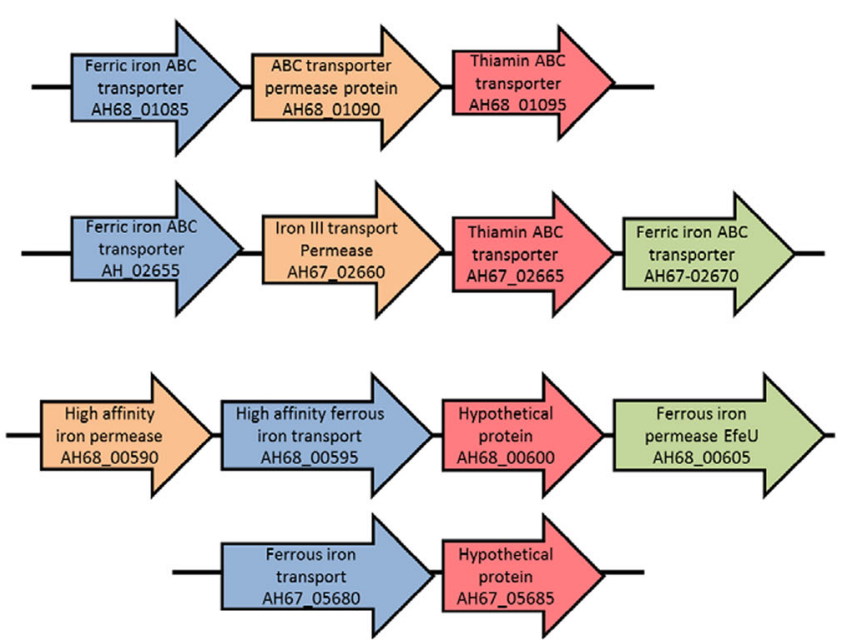

Fig. 1 Ferric and ferrous operons identified in the genome of B. kashiwanohense PV2O-2 (AH_68) and B. pseudolongum PV8-2 (AH_67). Homologous genes are indicated by the same colors 


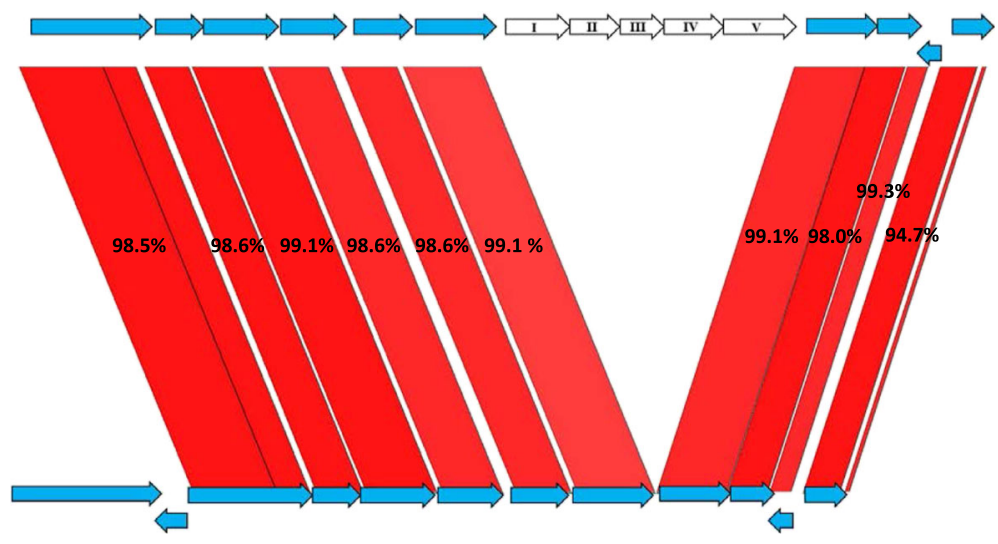

Fig. 2 Genetic organization of the ferric operon of B. pseudolongum PV8-2 and comparison of the region to B. pseudolongum AGR2145. Homologous genes are linked with red lines and their degree of identity provide as percentage of identity. The inserted genes in B. pseudolongum PV8-2 are indicated in white: I: Ferric iron ABC transporter, iron-binding, II: IRON(III)-Transport system permease protein, III: Thiamin ABC transporter, transmembrane, IV: Ferric iron ABC transporter, ATP-binding protein, V: COG family: predicted phosphohydrolases

secretion pathways, and $32(29 \%)$ were previously reported to be extracellular (Fig. 3). In PV8-2, 92 proteins were identified in the exoproteome (Additional file 4: Table S5). Of these, 28 (30\%) were predicted to contain a classical signal peptide, 34 (36\%) were predicted to be secreted by a non-classical secretion pathway and 30 (33\%) were previously reported to be extracellular (Fig. 3). Of the 112 identified proteins in PV20-2, 66 proteins had a homologue in the secretome of PV8-2 (Table 1).

Remarkably, the secretome of PV8-2 contained a ferric - iron transporter (AH67_02660) but no ferric transporter was detected. In contrast, secretome of PV20-2 contained three ferrous iron transporters AH68_00590, AH68_00595 and AH68_00600. In addition, the ABCtransporter genetically linked to the putative siderophore genes (AH68_05505) was found. Among the proteins identified in both secretomes were 3 elongation factors, a glyceraldehyde-3-phosphate dehydrogenase, proteins related to stress and transporters, including the zinc $A B C$ transporter ZnuA (Table 1). A second protein with zinc binding function (ZinT, locus tag AH67_08575) was identified in PV8-2 secretome (Additional file 4: Table S5). Further, some clear surface related proteins were identified such as a penicillin binding protein and a membrane protein. In the exoproteome of PV8-2 a lysozyme M1 (AH67_08110) was identified.

\section{Discussion}

In this study we analyzed two bifidobacteria strains that had the highest iron sequestration capacity among 56 bifidobacterial isolates from stools of iron - deficient Kenyan infants [12]. Using a comparative genomics and a combined proteomic-genomic approach we identified in both strains specific adaptations to the low iron concentration encountered in the GI-tract of iron-deficient infants.

The comparative genome analyses revealed adaptations to low iron conditions and to a specific diet, thus the genomic content reflects the source of the strains, as already proposed previously for bifidobacteria [36]. B. kashiwanohense PV20-2 encodes genes putatively involved in bacillibactin and pyoverdines syntheses that were not present in strain DSM 21854. Bacillibactins and pyoverdines are both siderophores $[34,35]$ and the corresponding genes in PV20-2 could encode for the synthesis of a bifidobacterial siderophore. The identification

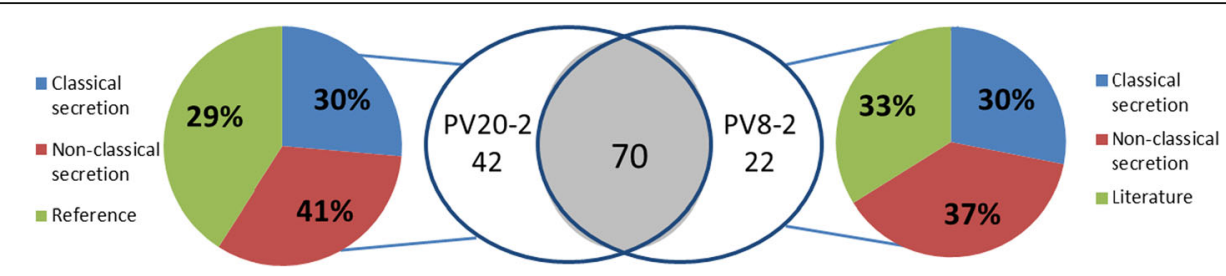

Fig. 3 Distribution of proteins in the secretome of PV20-2 (B. kashiwanohense PV20-2) and PV8-2 (B. pseudolongum PV8-2). Colored circles show the fraction of proteins secreted by classical secretion pathway (blue), non-classical secretion pathway (red) and identified in literature (green). Right circle, represent the percentage of proteins identified in PV8-2 secreted classical secretion pathway ( $\mathrm{N}$-terminal sequence, blue), non-classical secretion pathway ( $\mathrm{N}$-terminal sequence, red) and the ones identified in literature (green) 
Table 1 Proteins identified in the exoproteome of B. kashiwanohense PV20-2 with an homologue in B. pseudolongum PV8-2

\begin{tabular}{|c|c|c|c|c|}
\hline Locus tag & Assigned function & Homologue in PV8-2 & $S P^{a}$ & Secreted $^{\mathrm{b}}$ \\
\hline AH68_05990 & membrane protein & AH67_04310 & & $x$ \\
\hline AH68_00170 & serine/threonine protein kinase & AH67_00415 & & $x$ \\
\hline AH68_00180 & penicillin-binding protein & AH67_00425 & $x$ & $x$ \\
\hline AH68_00315 & peptidase & AH67_00490 & & $x$ \\
\hline AH68_00635 & membrane protein & AH67_00835 & & $x$ \\
\hline AH68_00655 & peptidase C69 & AH67_00865 & & $x$ \\
\hline AH68_00900 & penicillin-binding protein & AH67_01125 & & $x$ \\
\hline AH68_00945 & phosphotransferase & AH67_01155 & & \\
\hline AH68_01075 & glycerol-3-phosphate acyltransferase & AH67_01265 & & \\
\hline AH68_01345 & glucose-6-phosphate isomerase & AH67_01530 & & \\
\hline AH68_01575 & phosphate $A B C$ transporter substrate-binding protein & AH67_01870 & $x$ & $x$ \\
\hline AH68_01610 & $50 S$ ribosomal protein $L 7$ & AH67_01905 & & \\
\hline AH68_01655 & molecular chaperone GroES & AH67_01950 & & \\
\hline AH68_01785 & $50 S$ ribosomal protein $L 4$ & AH67_02085 & & \\
\hline AH68_01885 & adenylate kinase & AH67_02185 & & \\
\hline AH68_02020 & hypothetical protein & AH67_02295 & $x$ & $x$ \\
\hline AH68_02050 & PTS mannose transporter subunit \|ABC & AH67_02320 & & $x$ \\
\hline AH68_02165 & amidase & AH67_02505 & & $x$ \\
\hline AH68_02170 & peptidase P60 & AH67_02510 & $x$ & $x$ \\
\hline AH68_02465 & $\begin{array}{l}\text { branched-chain amino acid } A B C \text { transporter } \\
\text { substrate-binding protein }\end{array}$ & AH67_02445 & $x$ & $x$ \\
\hline AH68_02570 & amidase & AH67_03020 & $x$ & $x$ \\
\hline AH68_02580 & $A B C$ transporter substrate-binding protein & AH67_03110 & $x$ & $x$ \\
\hline AH68_02785 & amino acid $A B C$ transporter substrate-binding protein & AH67_06815 & $x$ & $x$ \\
\hline AH68_02795 & methionine $\mathrm{ABC}$ transporter ATPase & AH67_06850 & $x$ & $x$ \\
\hline AH68_02900 & arylsulfatase & AH67_03300 & & $x$ \\
\hline AH68_03085 & elongation factor $G$ & AH67_03425 & & \\
\hline AH68_03090 & elongation factor Tu & AH67_03430 & & \\
\hline AH68_03095 & elongation factor $\mathrm{P}$ & AH67_03450 & & $x$ \\
\hline AH68_03260 & molecular chaperone GroEL & AH67_03615 & & \\
\hline AH68_03390 & ABC transporter substrate-binding protein & AH67_03690 & $x$ & \\
\hline AH68_03430 & Clp protease & AH67_05875 & & \\
\hline AH68_03845 & hypothetical protein & AH67_05645 & & $x$ \\
\hline AH68_03865 & enolase & AH67_05625 & & \\
\hline AH68_03915 & transcription elongation factor GreA & AH67_05585 & & \\
\hline AH68_03955 & transcriptional regulator & AH67_05555 & $x$ & $x$ \\
\hline AH68_03970 & hypothetical protein & AH67_05545 & $x$ & $x$ \\
\hline AH68_04025 & $A B C$ transporter substrate-binding protein & AH67_05490 & $x$ & $x$ \\
\hline AH68_04165 & acetate kinase & AH67_05125 & & \\
\hline AH68_04240 & hypothetical protein & AH67_05000 & & $x$ \\
\hline AH68_04280 & hypothetical protein & AH67_04940 & & $x$ \\
\hline AH68_04600 & $A B C$ transporter substrate-binding protein & AH67_00280 & $x$ & $x$ \\
\hline AH68_05530 & choloylglycine hydrolase & AH67_04680 & & $x$ \\
\hline
\end{tabular}


Table 1 Proteins identified in the exoproteome of B. kashiwanohense PV20-2 with an homologue in B. pseudolongum PV8-2 (Continued)

\begin{tabular}{|c|c|c|c|c|}
\hline AH68_05760 & transaldolase & AH67_04590 & & \\
\hline AH68_05765 & transketolase & AH67_04585 & & \\
\hline AH68_06400 & glutamine synthetase & AH67_03825 & & \\
\hline AH68_06950 & peptidylprolyl isomerase & AH67_05945 & & \\
\hline AH68_07210 & $A B C$ transporter substrate-binding protein & AH67_06260 & $x$ & $x$ \\
\hline AH68_07300 & glyceraldehyde-3-phosphate dehydrogenase & AH67_06350 & & \\
\hline AH68_07370 & peptide $A B C$ transporter substrate-binding protein & AH67_06260 & $x$ & $x$ \\
\hline AH68_07705 & Lon protease & AH67_06760 & & $x$ \\
\hline AH68_08215 & hypothetical protein & AH67_07275 & & $x$ \\
\hline AH68_08365 & glycine cleavage system protein $\mathrm{H}$ & AH67_07395 & & \\
\hline AH68_08385 & thioredoxin & AH67_07415 & & \\
\hline AH68_08390 & hypothetical protein & AH67_07420 & & $x$ \\
\hline AH68_08925 & hypothetical protein & AH67_07735 & $x$ & $x$ \\
\hline AH68_08940 & peptidylprolyl isomerase & AH67_07745 & $x$ & $x$ \\
\hline AH68_08975 & ATP synthase FOF1 subunit B & AH67_07780 & & $x$ \\
\hline AH68_09035 & inorganic pyrophosphatase & AH67_07840 & & \\
\hline AH68_09070 & hypothetical protein & AH67_07875 & & $x$ \\
\hline AH68_09115 & glutamyl-tRNA amidotransferase & AH67_07920 & & \\
\hline AH68_09245 & single-stranded DNA-binding protein & AH67_08040 & & $\mathrm{x}$ \\
\hline AH68_09250 & $30 S$ ribosomal protein $\mathbf{S 6}$ & AH67_08045 & & \\
\hline AH68_09340 & phosphoglycerol transferase & AH67_08095 & & $x$ \\
\hline AH68_09765 & heat shock protein GrpE & AH67_08330 & & $x$ \\
\hline AH68_09770 & molecular chaperone DnaK & AH67_08335 & & $x$ \\
\hline AH68_10135 & sugar $A B C$ transporter ATP-binding protein & AH67_08590 & & \\
\hline
\end{tabular}

${ }^{a}$ signal peptide predicted according to [22]

bas predicted by SecretomeP 2.0

in the secretome of an $\mathrm{ABC}$-transporter genetically linked to the putative siderophore genes suggest that this transporter is involved in the uptake of the iron-siderophore complex. In the B. pseudolongum PV8-2 strain, iron related genome content included a ferric iron transporter clearly inserted in the genome (Fig. 2). The GC-content of $59.4 \%$ of the insertion suggests it has been acquired from a high-GC-content bacterium. It is, however, not known when the insertion occurred and it is therefore also possible that the sequence is already adapted to the host chromosome for its GC-content. The origin of this insertion is therefore not clear. The presence of a siderophore operon in strain PV20-2 and an additional iron transporter in PV8-2 seems directly related to the selective pressure mediated by the low-iron abundance in the gut of the iron-deficient infants.

Arabinogalactan are pectin derived sugars that can be utilized by some bifidobacteria [37] and the corresponding genes have been described in B. breve [38]. Arabinogalactan is found in plant cell wall and is a potential prebiotic with some selectivity for bifidobacteria [39]
The occurrence of an arabinogalactan machinery in the human isolate PV8-2, and not in the rumen isolates DSM 20092 and AGR 2145 might be related to the specific diet of the Kenyan infant from whom feces the strain was isolated. The infant weaning diet is composed of mother's milk and maize porridge cooked in water, and therefore containing arabinogalactan-rich source [40].

Approximately $75 \%$ of the CDSs that were unique for PV8-2 and PV20-2 in the direct comparison to strains of their own species were found in other bifidobacteria. This suggests that the corresponding genes have been acquired from other bifidobacteria and that horizontal gene transfer (HGT) occurs between members of the phylum. In addition, the ferric iron operon of PV20-2 is inserted in a conserved genome region and likely acquired via HGT. The high cell densities and strong selective pressure in the GI-tract facilitate HGT and outgrowth of novel variants [41, 42]. In addition, costs of gene transfer are lower if the genes fit well in the recipient's system and transfer occurs therefore easier between related species [43]. The occurrence of a whole set of genes horizontal through the genus 
strongly suggests that HGT events occur frequently between bifidobacteria. The unique genes of PV20-2 and PV8-2 encoded mostly hypothetical or phage related functions, paralleling an observation in the B. breve taxon [44].

Bacteria, including bifidobacteria, secrete proteins to ensure the acquisition of essential nutrients, cell to cell communication, and competition in their respective niches [45]. Extracellular proteins related to iron metabolism, adhesion and antimicrobial activity were identified in the secretome of PV8-2 and PV20-2. Both strains apparently use therefore a combination of strategies to efficiently compete and interact with the environment. This observation is in agreement with recent observations that several mechanisms are used by bacteria to compete in different environments [46-49]. Furthermore, the ability of bacteria to occupy specific environments mainly relies on their ability to obtain adequate supplies of nutrients that are indispensable for their growth, such as iron $[50,51]$. In the exoproteome of $B$. kashiwanohense PV20-2 three ferrous iron transporters were identified which seems directly related to the high iron internalization activity of the strain [12]. In contrast, in the exoproteome of PV8-2 a ferric iron transporter was identified. This suggests different iron acquisition strategies in both strains. Remarkably, the ferric transporter of PV8-2 is likely acquired via HGT and its occurrence in the secretome shows that it is active. The absence of ferrous transporter proteins in the secretome suggests that the acquired ferric transporter has taken over the function for iron uptake. The competition for iron within the gut microbiota and the limited availability of iron in the intestine, leads to a constant battle for iron between the enteric microbiota and the host $[7,52,53]$. Thus efficient iron acquisition mechanisms are likely pivotal for proliferation and persistence in the gut $[14,16,54]$. Production of iron binding proteins by bifidobacteria may also limit the iron available for pathogens thus potentially being implicated in a so called nutritional immunity phenomenon [55-57]. In competition, inhibition, and displacement assays using HT29-MTX cell lines, strain PV8-2 reduces adhesion of Salmonella Typhimurium and Escherichia coli O157:H45 while strain PV20-2 only reduced adhesion of $S$. Typhimurium [58]. This competitive strength of especially PV8-2 might be in part due to iron binding mechanism limiting iron availability for pathogens.

The zinc $A B C$ transporter ZnuA was identified in the exoproteome of both strains. Zinc metal transporters may facilitate, although to a lesser extent, the uptake of other divalent ions, such as iron [59]. Alternatively, their detection may be the result of a common micronutrient stress sensing. Further, ZinT was identified in PV8-2. ZinT forms a complex with ZnuA to enhance its activity. ZinT was identified in the extracellular fraction of enterohemorrhagic $E$. coli where it was important for colonization [60, 61]. Zinc competition in the intestine may also play a role in nutritional immunity and control of enteropathogens growth, but further research is needed to confirm the beneficial effects of zinc sequestration in the gut environment [14, 47].

Elongation factors have been found in the secretome lactobacilli and are involved in the adhesion Lactobacillus johnsonii to human intestinal cells and mucins [62, 63]. Their presence in the secretome and the high adhesion properties of both strains [64] suggests a similar role for these factors in bifidobacteria. Similarly, glyceraldehyde-3phosphate dehydrogenases, and the stress proteins GroEL and DnaK were previously shown to be involved in adhesion of lactobacilli [65-68], and their occurrence in the secretome of PV20-2 and PV8-2 suggests same functionality.

The vast majority of the proteins identified in both secretomes possess an $\mathrm{N}$-terminal signal peptide, and are predicted to be secreted, or were already shown to be extracellular (Additional file 4: Table S4 and S5). In addition, many proteins were predicted to be lipoproteins, while lipoproteins of bifidobacteria were reported to stimulate the immune system and were involved in adhesion $[69,70]$. However, the implication of these proteins in more than one function has to be further tested. Furthermore, the lysozyme M1 might be involved in inhibition against competing microorganisms. Lysozymes or glycoside hydrolases such as $\mathrm{N}$-acetylmuramidases are reported to be involved in competition and antimicrobial activity because they can act as bacteriolysins [71].

\section{Conclusions}

In our study we used genomics and proteomics to characterize the response to low iron conditions of $B$. kashiwanohense PV20-2 and B. pseudolongum PV8-2, selected for their high iron sequestration properties. The expression of ferric and ferrous binding proteins and the different responses to iron limitation reflect strain specific characteristics, which is in agreement with high strain variation among bifidobacteria. In addition, to the ferrous iron operon identified in the genome of both studied strains, PV8-2 was shown to have a specific ferric iron operon. The iron binding proteins identified in this study are likely involved in iron metabolism. By combining functional assays and genomics and proteomic tools we could uncover ironsequestration mechanisms that could provide important competition edge for colonization in the low iron environment of the infant gut. However, the specific function of the extracellular proteins disclosed in this study and their role in the GI-tract colonization remain to be investigated.

\section{Methods}

\section{Strains and growth conditions}

B. kashiwanohense PV20-2 and B. pseudolongum PV8-2 were previously isolated from stool samples of iron 
deficient Kenyan infants [12]. Pre-cultures were performed in MRS broth (Biolife, Italy), supplemented with $0.5 \mathrm{~g} / \mathrm{L}$ L-cysteine (Sigma-Aldrich, Switzerland), anaerobically at $37{ }^{\circ} \mathrm{C}$ in Hungate tubes with $\mathrm{CO}_{2}$ headspace (PanGas, Switzerland). Growth was monitored in a Biowave CO8000 spectrophotometer (Biochrom England). Pre-cultures with an $\mathrm{OD}_{600}$ of 1.5 were centrifuged and cells were suspended in peptone water (Oxoid, Switzerland) supplemented with $0.05 \%$ L-cystein, $\mathrm{pH} 6.5$. A portion of $3.75 \mathrm{~mL}$ of this suspension was used to inoculate $250 \mathrm{~mL}$ of a chemically semi-defined medium with an iron concentration of $1.5 \mu \mathrm{M}$ described previously [12]. The iron concentration in the media was measured using a graphite furnace atomic absorption spectrophotometer (AA-240Z, Varian Inc., Australia) according to manufacturer's instructions [72]. Cultures were incubated at $37^{\circ} \mathrm{C}$ under anaerobic conditions until an $\mathrm{OD}_{600 \mathrm{~nm}} 1.5$ (corresponding to the early stationary phase). Three biological replicates were performed.

\section{Analyses of the genomes of B. kashiwanohense PV20-2 and $B$. pseudolongum PV8-2}

The genomes of B. kashiwanohense PV20-2 (Genbank accession number CP007456), and B. pseudolongum PV8-2 (CP007457) were compared to a local database containing the genomes of 42 completely sequenced and 40 draft genomes of bifidobacteria (Additional file 1: Table S1), using the tBLASTn algorithm [73] embedded in the CLC genomic workbench 7.0 (CLC genomics, Denmark). The E-value cut off was set at $<1$ exp-4, as was used previously for comparative genomics of bifidobacteria [74]. Comparisons of genetic organization were visualized by the Artemis Comparison viewer [75] with input files that were produced using Double Act version 2 (http:// www.hpa-bioinfotools.org.uk/pise/double_act.html).

Coding sequences (CDS) were predicted from the genome and signal peptides were identified using SignalP 4.1 (http://www.cbs.dtu.dk/services/SignalP, [22]) with the option "Gram-Positive" bacteria as organism group, default D-cutoff values (0.45) and transmembrane regions included. Non-classical protein secretion was predicted with SecretomeP 2.0 (http://www.cbs.dtu.dk/ services/SecretomeP, [76]) with Gram-positive bacteria selected as organism group. A protein with signal peptide was considered when the SecP score was above 0.5. Lipoproteins were identified using PredLipo with default parameters [77].

\section{Extraction of extracellular proteins and 1D gel electrophoresis}

Cultures were centrifuged at $10,000 \times g$ at $4{ }^{\circ} \mathrm{C}$ for $10 \mathrm{~min}$ and the supernatants were passed through a $0.22 \mu \mathrm{m}$ pore size filter (Millipore, Switzerland). Proteins in the supernatant were precipitated with $10 \% \mathrm{v} / \mathrm{v}$ trichloroacetic acid (Sigma-Aldrich) at $4{ }^{\circ} \mathrm{C}$ for $3 \mathrm{~h}$ and harvested by centrifugation at $11,000 \times g$ at $4{ }^{\circ} \mathrm{C}$ for $30 \mathrm{~min}$. The precipitate was washed twice with ice-cold acetone, dried in a centrifugal vacuum concentrator (Vacufuge 5301, Eppendorf, Switzerland), and stored at $-20{ }^{\circ} \mathrm{C}$ until further use. Protein pellets were solubilized in $250 \mu \mathrm{L}$ of $50 \mathrm{mM}$ ammonium bicarbonate at $\mathrm{pH} 8.5$ (AmBic). Protein concentrations were determined according to Bradford using Bradford reagent (Sigma Aldrich) and bovine serum albumin as standard.

Tricine sodium-dodecyl sulfate polyacrylamide gel electrophoresis was used to separate the proteins [78]. The precipitated proteins were mixed 1:1 with Tricine Laemmli sample buffer (Biorad, Switzerland), as described by manufacturer's instructions, and incubated for $7 \mathrm{~min}$ at $99{ }^{\circ} \mathrm{C}$ in a Dri-Block (Witec, Switzerland). $50 \mu \mathrm{g}$ of standardized protein mixture was loaded on a $10-20 \%$ Tris-Tricine Mini-Protean TGX precast gel (Biorad), with tris-tricine as running buffer (Biorad, Switzerland). The gel was run at $180 \mathrm{~V}$ for $40 \mathrm{~min}$, stained with Coomassie blue G250 and destained with 10\% (v/v) acetic acid (Sigma-Aldrich). Gel lanes were cut in eight fractions and prepared for mass spectrometry analysis as described previously [79], with slight modifications. Briefly, gel fractions were washed twice with $50 \mathrm{mM}$ AmBic / 5\% acetonitrile (ACN) and dehydrated using 100\% ACN. Subsequently, gel pieces were treated with sequencing grade trypsin (Promega, Switzerland) for $1 \mathrm{~h}$ at $4{ }^{\circ} \mathrm{C}$ according to manufacturer's instructions. Thereafter, $50 \mu$ l digestion buffer containing $50 \mathrm{mM}$ AmBic, pH 8.5 was added, followed by incubation at $37{ }^{\circ} \mathrm{C}$ for $16 \mathrm{~h}$. The generated tryptic peptides were extracted with $0.1 \%$ trifluoroacetic acid $/ 50 \%$ $\mathrm{ACN} v / \mathrm{v}$ at $37^{\circ} \mathrm{C}$ in an ultrasonicator (VWR, Switzerland) for $15 \mathrm{~min}$ and finally concentrated with a vacuum concentrator. Peptides were desalted using ZipTip $\mathrm{C}_{18}$ micro-columns (Millipore, Switzerland) following the manufacturer's instructions, and finally dried in a vacuum concentrator. The dried peptide mixture was suspended in $5 \% \mathrm{ACN} / 0.1 \%$ formic acid $\mathrm{v} / \mathrm{v}$ for LC-MS/MS measurements.

\section{Acquisition of proteome data}

All data were acquired on an LTQ OrbitrapVelos mass spectrometer connected with an Easy-nLC 1000 HPLC system (Thermo Fisher Scientific, Germany). Peptide samples $(4 \mu \mathrm{L})$ were loaded onto a frit column $(75 \mu \mathrm{m}$ inner diameter) packed with reverse phase C18 material AQ with $3 \mu \mathrm{m}$ particle size and $200 \AA$ pore size (Bischoff $\mathrm{GmbH}$, Leonberg, Germany), and eluted with a flow rate of $300 \mathrm{~nL}$ per min. Solvent composition of buffer A was $0.1 \%$ formic acid in water, and buffer B contained $0.1 \%$ formic acid in acetonitrile. The following liquid chromatography gradient was applied: 0 min: $0 \%$ buffer B, 90 min: 30\% B, 92 min: 100\% B, $100 \mathrm{~min}: 100 \%$ B. 
Survey scans were recorded in the Orbitrap mass analyzer in the range of $\mathrm{m} / \mathrm{z} 300-2000$, with a resolution of 30000 at $\mathrm{m} / \mathrm{z}$ 400. Collision-induced dissociation (CID) spectra were acquired in the ion trap, from the 20 most intense signals above a threshold of 1000 counts. A normalized collision energy of $35 \%$ and an activation time of $10 \mathrm{~ms}$ were used for CID. The precursor ion isolation width was set to $\mathrm{m} / \mathrm{z} 2.0$. Charge state screening was enabled, and single charged ions and unassigned charge states were rejected. Precursor masses already selected for MS/MS acquisition were excluded for further selection during $45 \mathrm{~s}$, and the exclusion window was 20 ppm.

\section{Protein identification}

Peak lists were generated with Mascot Distiller 2.4.1 from Matrix Science using the Thermo MSFile Reader 2.2. Mascot Daemon 2.4 was used for merging and submitting the.mgf files from Xcalibur FT package 2.0.7. The resulting mass spectra files obtained from mass spectrometry analysis were searched using Mascot 2.4.1 (Matrix Science, London, UK) and 2 databases each containing the RAST [80] predicted coding sequences (CDS) of one Bifidobacterium strain, i.e., 2,077 CDS for B. kashiwanohense PV20-2 and 1704 CDS for B. pseudolongum PV8-2. Mascot search parameters were tryptic peptides with a maximum of one missed cleavage during proteolytic digestion, mass tolerances of $7 \mathrm{ppm}$ on the parent ion and 0.7 Da on the MS/ MS. Oxidation of methionine $(\mathrm{M})$ and pyroglutamate formation from $\mathrm{N}$-terminal glutamine (N-term $\mathrm{Q})$ were set as variable modifications. Scaffold 4.3 from Proteome Software was used to validate MS/MS based peptide and protein identifications using Mascot and X!Tandem cyclone 2010.12.01.1. Protein probabilities were assigned by the Protein Prophet algorithm [81]. Peptide and protein identifications were accepted when less than 1\% False Discovery Rate was achieved. The function MudPit was used to group the eight fractions in each of the three biological replicates. Finally, a protein was considered valid when it was identified in all three biological replicates, at least two different peptides were detected, a signal peptide with one of the two predictors was found and/or reported to be extracellular.

\section{Additional files}

Additional file 1: "PVazquez etal_additional file_1". The file contains the following 2 tables: Table $\mathbf{S} 1 \mathrm{a}$. Complete sequenced genomes of bifidobacteria used in this study and their Genbank accession numbers (sheet 1) and Table S1b. Contigs of partially sequenced bifidobacteria used in this study and their Genbank accession numbers (sheet 2). (XLSX $62 \mathrm{~kb}$ )

Additional file 2: "PVazquez_etal_additional_file_2". The file contains the following 2 tables: Table S2a. Genes uniquely found in PV20-2 when compared to all bifidobacteria (sheet 1) and Table S2b. Genes uniquely found in PV20-2 compared to DSM21854 (sheet 2). (XLSX $35 \mathrm{~kb}$ )
Additional file 3: "PVazquez etal additional file 3". The file contains the following 2 tables: Table S3a. Genes uniquely found in PV8-2 when compared to all bifidobacteria (sheet 1) and Table S3b. Genes uniquely found in PV8-2 compared to AGR 2145 and DSM20092 (sheet 2). (XLSX $13 \mathrm{~kb}$ )

Additional file 4: "PVazquez_etal_additional_file_3". The file contains the following tables: Table S4. Proteins identified in the exoproteome of B. kashiwanohense PV20-2. Table S5. Proteins identified in the exoproteome of B. pseudolongum PV8-2. (XLSX $23 \mathrm{~kb}$ )

\section{Abbreviations}

Gl: Gastro-intestinal; HGT: Horizontal gene transfer; MS: Mass spectra; PV20-2: B. kashiwanohense PV20-2; PV8-2: B. pseudolongum PV8-2

\section{Acknowledgement}

Not applicable.

\section{Funding}

This research was supported by own resources at ETH Zurich, Zurich Switzerland

\section{Availability of data and material}

Data presented in this study are available in ProteomeXchange (www.proteomexchange.org) under accession numbers PXD001451 and PXD001452 for PV20-2 and PV8-2, respectively.

\section{Authors' contribution}

PVG, CC, and $C L$ designed the research. PVG, SBO, PG, MS performed experiments. CC, MS and $C L$ supervised the research. PVG, SBO, PG, and MS analyzed the data. PVG, CC, MS and CL wrote the manuscript. All authors read and approved the final manuscript.

\section{Competing interests}

The authors declare that they have no competing interests.

\section{Consent for publication}

All authors agree on publication.

Ethics approval and consent to participate Not applicable.

\section{Author details}

'Laboratory of Food Biotechnology, ETH Zurich, Institute of Food, Nutrition and Health, Schmelzbergstrasse 7, 8092 Zurich, Switzerland. 'Functional Genomics Center Zurich, Winterthurerstrasse 190, 8057 Zurich, Switzerland. ${ }^{3}$ Present Address: Institut National de la Recherche Agronomique, UR 545 URF, 15000 Aurillac, France.

Received: 18 May 2016 Accepted: 26 December 2016

Published online: 06 January 2017

\section{References}

1. Andreini C, Bertini I, Cavallaro G, Holliday GL, Thornton JM. Metal ions in biological catalysis: from enzyme databases to general principles. J Biol Inorg Chem. 2008;13(8):1205-18.

2. Zimmermann MB, Hurrell RF. Nutritional iron deficiency. Lancet. 2007;370(9586):511-20.

3. Zimmermann MB, Chassard C, Rohner F, N'Goran EK, Nindjin C, Dostal A, Utzinger J, Ghattas H, Lacroix C, Hurrell RF. The effects of iron fortification on the gut microbiota in African children: a randomized controlled trial in Cote d'Ivoire. Am J Clin Nutr. 2010;92(6):1406-15.

4. Kortman GA, Raffatellu M, Swinkels DW, Tjalsma H. Nutritional iron turned inside out: intestinal stress from a gut microbial perspective. FEMS Microbiol Rev. 2014;38:1202-34.

5. Collins HL. Withholding iron as a cellular defence mechanism - friend or foe? Eur J Immunol. 2008;38(7):1803-6.

6. Raffatellu M, George MD, Akiyama Y, Hornsby MJ, Nuccio SP, Paixao TA Butler BP, Chu H, Santos RL, Berger T, et al. Lipocalin-2 resistance confers an advantage to Salmonella enterica serotype Typhimurium for growth and survival in the inflamed intestine. Cell Host Microbe. 2009;5(5):476-86. 
7. Nairz M, Schroll A, Sonnweber T, Weiss G. The struggle for iron - a metal at the host-pathogen interface. Cell Microbiol. 2010;12(12):1691-702.

8. Foligne B, Daniel C, Pot B. Probiotics from research to market: the possibilities, risks and challenges. Curr Opin Microbiol. 2013;16(3):284-92.

9. Backhed F, Ley RE, Sonnenburg JL, Peterson DA, Gordon Jl. Host-bacterial mutualism in the human intestine. Science. 2005;307(5717):1915-20.

10. Ventura M, Turroni F, van Sinderen D. Probiogenomics as a tool to obtain genetic insights into adaptation of probiotic bacteria to the human gut. Bioeng Bugs. 2012;3(2):73-9.

11. Ventura M, Turroni F, Motherway MO, MacSharry J, van Sinderen D. Host-microbe interactions that facilitate gut colonization by commensal bifidobacteria. Trends Microbiol. 2012;20(10):467-76.

12. Vazquez-Gutierrez P, Lacroix C, Jaeggi T, Zeder C, Zimmerman M, Chassard C Bifidobacteria strains isolated from stools of iron deficient infants can efficiently sequester iron. BMC Microbiol. 2015;15(1):3.

13. Bailey JR, Probert CS, Cogan TA. Identification and characterisation of an iron-responsive candidate probiotic. PLoS One. 2011;6(10):e26507.

14. Kehl-Fie TE, Skaar EP. Nutritional immunity beyond iron: a role for manganese and zinc. Curr Opin Chem Biol. 2010;14(2):218-24.

15. Liu JZ, Jellbauer S, Poe AJ, Ton V, Pesciaroli M, Kehl-Fie TE, Restrepo NA, Hosking MP, Edwards RA, Battistoni A, et al. Zinc sequestration by the neutrophil protein calprotectin enhances Salmonella growth in the inflamed gut. Cell Host Microbe. 2012;11(3):227-39.

16. Diaz-Ochoa VE, Jellbauer S, Klaus S, Raffatellu M. Transition metal ions at the crossroads of mucosal immunity and microbial pathogenesis. Front Cell Infect Microbiol. 2014;4:2.

17. Sanchez B, Urdaci MC, Margolles A. Extracellular proteins secreted by probiotic bacteria as mediators of effects that promote mucosa-bacteria interactions. Microbiology. 2010;156(Pt 11):3232-42.

18. Christie-Oleza JA, Pina-Villalonga JM, Bosch R, Nogales B, Armengaud J. Comparative proteogenomics of twelve Roseobacter exoproteomes reveals different adaptive strategies among these marine bacteria. Mol Cell Proteomics. 2012;11(2):M111-013110.

19. Armengaud J. Microbiology and proteomics, getting the best of both worlds! Environ Microbiol. 2013;15(1):12-23.

20. Gil C, Monteoliva L. Trends in microbial proteomics. J Proteomics. 2014;97:1-2.

21. Yang XY, Lu J, Sun $X$, He QY. Application of subproteomics in the characterization of Gram-positive bacteria. J Proteomics. 2012;75(10):2803-10.

22. Armengaud J, Christie-Oleza JA, Clair G, Malard V, Duport C. Exoproteomics: exploring the world around biological systems. Expert Rev Proteomics. 2012;9(5):561-75.

23. Turroni F, Serafini F, Foroni E, Duranti S, O'Connell Motherway M, Taverniti V, Mangifesta M, Milani C, Viappiani A, Roversi T, et al. Role of sortase-dependent pili of Bifidobacterium bifidum PRL2010 in modulating bacterium-host interactions. Proc Natl Acad Sci U S A. 2013;110(27):11151-6.

24. Turroni F, Serafini F, Mangifesta M, Arioli S, Mora D, van Sinderen D, Ventura M. Expression of sortase-dependent pili of Bifidobacterium bifidum PRL2010 in response to environmental gut conditions. FEMS Microbiol Lett. 2014:357(1):23-33.

25. Ventura $M$, Turroni F, Lugli GA, van Sinderen D. Bifidobacteria and humans: our special friends, from ecological to genomics perspectives. J Sci Food Agric. 2014;94(2):163-8.

26. Joyce $A R$, Palsson BO. The model organism as a system: integrating 'omics' data sets. Nat Rev Mol Cell Biol. 2006;7(3):198-210.

27. Lee IC, Tomita S, Kleerebezem M, Bron PA. The quest for probiotic effector molecules-unraveling strain specificity at the molecular level. Pharmacol Res. 2013;69(1):61-74.

28. Seraphin B, Hettich R. Microbial proteomics: the quiet revolution. Curr Opin Microbiol. 2012;15(3):348-50.

29. Del Chierico F, Petrucca A, Vernocchi P, Bracaglia G, Fiscarelli E, Bernaschi P, Muraca M, Urbani A, Putignani L. Proteomics boosts translational and clinical microbiology. J Proteomics. 2014;97:69-87.

30. Renuse S, Chaerkady R, Pandey A. Proteogenomics. Proteomics. 2011:11(4):620-30.

31. Vazquez-Gutierrez P, Lacroix C, Chassard C, Klumpp J, Jans C, Stevens MJ. Complete and Assembled Genome Sequence of Bifidobacterium kashiwanohense PV20-2, Isolated from the Feces of an Anemic Kenyan Infant. Genome Announc. 2015;3(1):e01467-14.

32. Vazquez-Gutierrez P, Lacroix C, Chassard C, Klumpp J, Stevens MJ, Jans C. Bifidobacterium pseudolongum Strain PV8-2, Isolated from a Stool Sample of an Anemic Kenyan Infant. Genome Announc. 2015;3(1):e01469-14.
33. Marchler-Bauer A, Bryant SH. CD-Search: protein domain annotations on the fly. Nucleic Acids Res. 2004;32(Web Server issue):W327-31.

34. Dertz EA, XU J, Stintzi A, Raymond KN. Bacillibactin-mediated iron transport in Bacillus subtilis. J Am Chem Soc. 2006;128(1):22-3.

35. Merriman TR, Merriman ME, Lamont IL. Nucleotide sequence of pvdD, a pyoverdine biosynthetic gene from Pseudomonas aeruginosa: PvdD has similarity to peptide synthetases. J Bacteriol. 1995;177(1):252-8.

36. Turroni F, van Sinderen D, Ventura M. Bifidobacteria: from ecology to genomics. Front Biosci. 2009;14:4673-84.

37. Crociani F, Alessandrini A, Mucci MM, Biavati B. Degradation of complex carbohydrates by Bifidobacterium spp. Int J Food Microbiol. 1994;24(1-2):199-210.

38. O'Connell Motherway M, Fitzgerald GF, van Sinderen D. Metabolism of a plant derived galactose-containing polysaccharide by Bifidobacterium breve UCC2003. Microb Biotechnol. 2011;4(3):403-16.

39. van den Broek LA, Hinz SW, Beldman G, Vincken JP, Voragen AG. Bifidobacterium carbohydrases-their role in breakdown and synthesis of (potential) prebiotics. Mol Nutr Food Res. 2008;52(1):146-63.

40. Jaeggi T, Kortman GA, Moretti D, Chassard C, Holding P, Dostal A, Boekhorst J, Timmerman HM, Swinkels DW, Tjalsma H, et al. Iron fortification adversely affects the gut microbiome, increases pathogen abundance and induces intestinal inflammation in Kenyan infants. Gut. 2015;64(5):731-42.

41. Haug MC, Tanner SA, Lacroix C, Stevens MJ, Meile L. Monitoring horizontal antibiotic resistance gene transfer in a colonic fermentation model. FEMS Microbiol Ecol. 2011;78(2):210-9.

42. Smillie CS, Smith MB, Friedman J, Cordero OX, David LA, Alm EJ. Ecology drives a global network of gene exchange connecting the human microbiome. Nature. 2011;480(7376):241-4.

43. Baltrus DA. Exploring the costs of horizontal gene transfer. Trends Ecol Evol. 2013;28(8):489-95.

44. Bottacini F, Medini D, Pavesi A, Turroni F, Foroni E, Riley D, Giubellini V, Tettelin $\mathrm{H}$, van Sinderen $\mathrm{D}$, Ventura $\mathrm{M}$. Comparative genomics of the genus Bifidobacterium. Microbiology. 2010;156(Pt 11):3243-54.

45. Schaible UE, Kaufmann SH. Iron and microbial infection. Nat Rev Microbiol. 2004;2(12):946-53.

46. Leal Jr SM, Roy S, Vareechon C, Carrion S, Clark H, Lopez-Berges MS, Di Pietro A, Schrettl M, Beckmann N, Redl B, et al. Targeting iron acquisition blocks infection with the fungal pathogens Aspergillus fumigatus and Fusarium oxysporum. PLoS Pathog. 2013;9(7):e1003436.

47. Haase H, Rink L. Multiple impacts of zinc on immune function. Metallomics. 2014;6:1175-80.

48. Johnson EE, Wessling-Resnick M. Iron metabolism and the innate immune response to infection. Microbes Infect. 2012;14(3):207-16.

49. Cerasi M, Ammendola S, Battistoni A. Competition for zinc binding in the host-pathogen interaction. Front Cell Infect Microbiol. 2013;3:108.

50. Marco ML, Pavan S, Kleerebezem M. Towards understanding molecular modes of probiotic action. Curr Opin Biotechnol. 2006;17(2):204-10.

51. Waldron KJ, Rutherford JC, Ford D, Robinson NJ. Metalloproteins and metal sensing. Nature. 2009;460(7257):823-30.

52. Monack DM. The battle in the gut. Immunity. 2014;40(2):173-5.

53. Raffatellu M, Baumler AJ. Salmonella's iron armor for battling the host and its microbiota. Gut Microbes. 2010;1(1):70-2

54. Cassat JE, Skaar EP. Iron in infection and immunity. Cell Host Microbe. 2013;13(5):509-19.

55. Stastna M, Van Eyk JE. Secreted proteins as a fundamental source for biomarker discovery. Proteomics. 2012:12(4-5):722-35.

56. Rohmer L, Hocquet D, Miller SI. Are pathogenic bacteria just looking for food? Metabolism and microbial pathogenesis. Trends Microbiol. 2011;19(7):341-8.

57. Weinberg ED. Iron availability and infection. Biochim Biophys Acta. 2009;1790(7):600-5.

58. Vazquez-Gutierrez P, de Wouters T, Werder J, Chassard C, Lacroix C. High iron sequestrating bifidobacteria inhibit enteropathogen growth and adhesion to intestinal epithelial cells in vitro. Front Microbiol. 2016;7:1480.

59. Cvetkovic A, Menon AL, Thorgersen MP, Scott JW, Poole 2nd FL, Jenney Jr FE, Lancaster WA, Praissman JL, Shanmukh S, Vaccaro BJ, et al. Microbial metalloproteomes are largely uncharacterized. Nature. 2010;466(7307):779-82.

60. Ho TD, Davis BM, Ritchie JM, Waldor MK. Type 2 secretion promotes enterohemorrhagic Escherichia coli adherence and intestinal colonization. Infect Immun. 2008;76(5):1858-65.

61. Gabbianelli R, Scotti R, Ammendola S, Petrarca P, Nicolini L, Battistoni A. Role of ZnuABC and ZinT in Escherichia coli 0157:H7 zinc acquisition and interaction with epithelial cells. BMC Microbiol. 2011;11:36. 
62. Granato D, Bergonzelli GE, Pridmore RD, Marvin L, Rouvet M, Corthesy-Theulaz IE. Cell surface-associated elongation factor Tu mediates the attachment of Lactobacillus johnsonii NCC533 (La1) to human intestinal cells and mucins. Infect Immun. 2004;72(4):2160-9.

63. Zhang Y, Xiang X, Lu Q, Zhang L, Ma F, Wang L. Adhesions of extracellular surface-layer associated proteins in Lactobacillus M5-L and Q8-L. J Dairy Sci. 2016;99(2):1011-8.

64. Vazquez Gutierrez P. Screening and characterization of bifidobacteria with high iron binding properties. Zurich: ETH Zurich; 2014.

65. Kinoshita H, Uchida H, Kawai Y, Kawasaki T, Wakahara N, Matsuo H, Watanabe M, Kitazawa H, Ohnuma S, Miura K, et al. Cell surface Lactobacillus plantarum LA 318 glyceraldehyde-3-phosphate dehydrogenase (GAPDH) adheres to human colonic mucin. J Appl Microbiol. 2008;104(6):1667-74.

66. Ramiah K, van Reenen CA, Dicks LM. Surface-bound proteins of Lactobacillus plantarum 423 that contribute to adhesion of Caco-2 cells and their role in competitive exclusion and displacement of Clostridium sporogenes and Enterococcus faecalis. Res Microbiol. 2008;159(6):470-5.

67. Sanchez B, Schmitter JM, Urdaci MC. Identification of novel proteins secreted by Lactobacillus plantarum that bind to mucin and fibronectin. J Mol Microbiol Biotechnol. 2009;17(3):158-62.

68. Katakura Y, Sano R, Hashimoto T, Ninomiya K, Shioya S. Lactic acid bacteria display on the cell surface cytosolic proteins that recognize yeast mannan. Appl Microbiol Biotechnol. 2010;86(1):319-26.

69. Guglielmetti S, Tamagnini I, Mora D, Minuzzo M, Scarafoni A, Arioli S, Hellman J, Karp M, Parini C. Implication of an outer surface lipoprotein in adhesion of Bifidobacterium bifidum to Caco-2 cells. Appl Environ Microbiol. 2008;74(15):4695-702.

70. Sengupta N, Alam SI, Kumar B, Kumar RB, Gautam V, Kumar S, Singh L. Comparative proteomic analysis of extracellular proteins of Clostridium perfringens type A and type C strains. Infect Immun. 2010;78(9):3957-68.

71. Butler E, Alsterfjord M, Olofsson TC, Karlsson C, Malmstrom J, Vasquez A. Proteins of novel lactic acid bacteria from Apis mellifera mellifera: an insight into the production of known extra-cellular proteins during microbial stress. BMC Microbiol. 2013;13:235.

72. Hoppler M, Egli I, Petry N, Gille D, Zeder C, Walczyk T, Blair MW, Hurrell RF. Iron speciation in beans (Phaseolus vulgaris) biofortified by common breeding. J Food Sci. 2014;79(9):C1629-34

73. Altschul SF, Gish W, Miller W, Myers EW, Lipman DJ. Basic local alignment search tool. J Mol Biol. 1990;215(3):403-10.

74. Lugli GA, Milani C, Turroni F, Duranti S, Ferrario C, Viappiani A, Mancabelli L, Mangifesta M, Taminiau B, Delcenserie V, et al. Investigation of the evolutionary development of the genus Bifidobacterium by comparative genomics. Appl Environ Microbiol. 2014;80(20):6383-94.

75. Carver TJ, Rutherford KM, Berriman M, Rajandream MA, Barrell BG, Parkhill J. ACT: the Artemis Comparison Tool. Bioinformatics. 2005;21(16):3422-3.

76. Bendtsen JD, Jensen LJ, Blom N, Von Heijne G, Brunak S. Feature-based prediction of non-classical and leaderless protein secretion. Protein Eng Des Sel. 2004;17(4):349-56.

77. Bagos PG, Tsirigos KD, Liakopoulos TD, Hamodrakas SJ. Prediction of lipoprotein signal peptides in Gram-positive bacteria with a Hidden Markov Model. J Proteome Res. 2008;7(12):5082-93.

78. Schagger H. Tricine-SDS-PAGE. Nat Protoc. 2006;1 (1):16-22.

79. Shevchenko A, Tomas H, Havlis J, Olsen JV, Mann M. In-gel digestion for mass spectrometric characterization of proteins and proteomes. Nat Protoc. 2006;1(6):2856-60

80. Aziz RK, Bartels D, Best AA, DeJongh M, Disz T, Edwards RA, Formsma K, Gerdes S, Glass EM, Kubal M, et al. The RAST Server: rapid annotations using subsystems technology. BMC Genomics. 2008;9:75.

81. Nesvizhskii Al, Keller A, Kolker E, Aebersold R. A statistical model for identifying proteins by tandem mass spectrometry. Anal Chem. 2003;75(17):4646-58.

\section{Submit your next manuscript to BioMed Central and we will help you at every step:}

- We accept pre-submission inquiries

- Our selector tool helps you to find the most relevant journal

- We provide round the clock customer support

- Convenient online submission

- Thorough peer review

- Inclusion in PubMed and all major indexing services

- Maximum visibility for your research

Submit your manuscript at www.biomedcentral.com/submit
Biomed Central 